\title{
AN EXAMINATION OF MULTIDIMENSIONAL POVERTY PROFILE IN LIMPOPO, SOUTH AFRICA: IMPLICATIONS FOR THE USE OF CBMS GENERATED DATA FOR INTEGRATED DEVELOPMENT PLANNING.
}

\author{
Grace Bicha Oloo* \\ Institute for Rural Development, University of Venda, South Africa \\ Email: *bichagrace@yahoo.com
}

\begin{abstract}
This study sought to establish the status of multidimensional poverty in Tzaneen Local Municipality in South Africa by using community-based system (CBMS). The objective was to profile multidimensional poverty on basic services and assess the usability of the generated data by local municipalities for Integrated development planning. Consultative, capacity building and CBMS design approach was adopted in the study. Administered household profile questionnaire was used on 1534 households. Indicators for poverty measurements were generated in partnership with Local municipality and aligned to Statistics South Africa. Data was captured using excel software and imported to CSPro6.3 software for creation of data dictionary and database. Data analysis was done using predetermined indicators and formulas. CBMS-NRDB software was used to generate poverty maps. Community validation approach was used to authenticate study findings. We conclude that CBMS generated multidimensional poverty data and maps can be used for formulating effective Integrated development plans and regular progress monitoring. The information can further be used to assess poverty policy implications at local levels. We recommend that Local municipality use CBMS generated data as a baseline for Integrated development planning and to compliment other national poverty surveys data.
\end{abstract}

Keywords: Poverty; integrated-development-plans; community based system, South Africa

\section{Introduction}

This study examines community -based multidimensional poverty and the implication of the generated data in Integrated development planning. There exists a long history of measuring the plight of the poor globally, dating back over a century (Statistics South Africa,2007). This is evident from its position on the world development agenda for instance, the Millennium Development Goals 2015 and Sustainable Development Goals 2030 (Statistics South Africa, 2008). Poverty can be construed in a narrow or broad sense. In the narrowest sense it means lack of income. In a broader sense poverty can be seen as multidimensional, encompassing other issues such as housing, health, education, access to services and other avenues of accessing resources (Studies in Poverty and Inequality Institute[SPII],2007). Community based Monitoring system (CBMS) is grounded on the principle that poverty can best be understood through the lives and experiences of the poor .Furthermore, it trails multidimensional poverty and development at the household level on regular intervals through a set of basic indicators (Reyes and Due, 2009).

Evidence-based decision making is increasingly becoming best practice which many countries including South Africa embrace. Poverty generated data is therefore key for developing evidence based policy and for setting appropriate strategies (Statistics South Africa,2008). Policy interventions on poverty therefore need to take into account sources of potential government failure and differences in local conditions (World Bank,2005). In South Africa, for example years of active discriminatory policymaking and neglect resulted in high levels of inequality (SPII,2006). The eradication of poverty, therefore, is one of the top priorities for the government (Oosthuizen, 2011). 
Over the past years, political interest sharpened the focus on poverty measurement and data sources regarding the extent to which poverty had increased or decreased in South Africa since 1994 dispensation (Bhorat and Kanbur,2005). It is worth noting that South Africa moved to a decentralized system as a means of bringing the government closer to the people. This move increased the demand for local information (South Africa Local Government Agency [SALGA], 2014) .Unfortunately, this shift to a decentralized government structures has not been accompanied by a corresponding shift in the statistical system (Reyes and Due, 2009). The statistical system has remained focused on meeting the information needs of central governments and sometimes provincial levels (Reyes and Due, 2009). The 5-year census gap conducted by statistics South Africa does not provide status of poverty at household levels making it difficult for the local municipalities to undertake effective planning (Statistics South Africa, 2016). Various efforts have therefore been made by the government to understand conditions at the ground. For example, the first Living Conditions Survey (LCS) conducted by Statistics South Africa (Stats SA) between September 2008 and August 2009 was to better understand the living conditions and for monitoring levels of poverty over time (Statistics South Africa, 2011). The large- scale community survey conducted by Statistics South Africa in 2016 to bridge the information gap between two censuses (Statistics South Africa, 2011, 2016). Unfortunately data was collected from only 1,3 million households across all South African communities (Statistics South Africa,2016). On the other hand, the decentralized structure of the South African local government demands for accurate data for effective planning and implementation of development projects (Integrated Development Plans [IDP], 2012).

\section{South Africa poverty reduction policies and strategies}

It is worth noting that South Africa poverty surveys and profiling is significantly institutionalized both in design and coverage at the national level. However, the non-existence of any institutional mechanism to generate poverty data at the local municipality levels remains a significant constraint in designing effective poverty agenda (Statistics South Africa,2008). Municipalities worldwide have developmental functions called Integrated Development planning which include promotion of social-economic development involving partnership with communities and stakeholders to which South Africa has also adopted (Development Bank of Southern Africa[DBSA],2000). The importance of addressing poverty and social inclusion at the local municipality levels has been identified and promoted in a number of policy documents in South Africa. Some of these documents include, National Plan Vision 2030, (2011), which sought to eliminate poverty and reduce inequality in South Africa. The White paper on local government which considers the Integrated Development Planning process as an instrument aimed at creating room for municipalities and communities to engage each other (Carrim,2001). The Municipal Structures Act of 1998, Municipal Systems Act 32 of 2000, amendment act, 2003 and Municipal structure amendment bill of 2016, which provided a framework for people to participate in budget processes and formulation of Integrated Development Planning. May, (2001) explained that monitoring takes into account the inputs made by governments and other stakeholders in the interventions that are intended to reduce poverty. This calls for the need for poverty generated data that can be shared by all stakeholders for effective integrated intervention strategies(Litman,2006).

Empirical literature demonstrate that poverty generated data has been used for various purposes. In South Africa, for example household surveys including the annual General Household Survey and the Labor Force data were used in exploring other dimensions of poverty such as hunger, employment levels and consequently earned incomes (Statistics South Africa, 2007). The community survey undertaken in 2005 was used to assess government services and the number of poor households that had no piped water and electricity (Statistics South Africa, 2005). Census Series was used to measure poverty at small area level (Tarozzi and Deaton 2009). In addition, the core expenditure module was designed to collect consumption data to update the Consumer Price Index basket of goods and service (United Nations [UN] 2005). In spite of the efforts made by the South African governemnt to conduct regular poverty monitoring surveys its efforts can best be regarded as limited and isolated. Moreover the macro-level analysis camouflage differences in poverty based on district and local municipal conditions ( May,2001). The key consideration in the intergarted development planning process are 
that the priority issues are derived from the existing local situation and focus on problems from the municiplaity, the community and development practitioners( DBSA,2000).

\section{Study Objectives}

The objective of this study was to profile the multidimensional poverty on a sample of three basic services, demonstrate the disaggregation of CBMS data through population demography and analyze the implication of the use of CBMS generated data in Integrated Development Planning.

\section{Methodology}

The implementation of the community based monitoring system methodology was used following a series of steps. The steps are explained in detail below.

\section{Advocacy/organization}

Data requirements was evaluated in conjunction with the Local economic development (LED) officials at the local municipality to identify existing gaps. A detailed work plan was developed that details the roles and commitment of all parties. Indicators for conduct of the study were developed in conjunction with the Local Economic development office and aligned with the data requirements. The indicators were also aligned with the National and provincial strategies on poverty reduction.

\section{Study design and data collection}

Data collection process was undertaken through a census covering 1534 households in the 8 villages across all localities by twenty-three trained enumerators. The traditional leaders provided respective household listings that were used to establish the authenticity of the households. Enumerators underwent training which took four days plus one-day field orientation and a two day field mentorship prior to actual data collection. Sample questionnaires were given to the enumerators to help in pre-testing the quality of the questionnaire.

This research employed a convergent design approach where equal priority was given to both quantitative and qualitative strands(Angell and Townsend, 2011). This approach provided a better understanding of causes of poverty, type and location of affected households. Household profile questionnaire and Ward level administrative questionnaires were used to collect data. The two questionnaires were accompanied by two manuals. Secondary data was collected from various literatures, research journals, periodicals, government official reports, Statistics South Africa, and the Internet. A statistical descriptive approach was used to interpret data. Collected data was edited and captured in excel spread sheet ready for consolidation coding and analysis.

\section{Data processing and Analysis}

Data processing was done using pre-set poverty dimensions indicators and formula. The CSPro 6.3 software was used to create data dictionary which described the organization of the data file. The use of CSPro 6.3 was convenient for the study because the language could be used to control the flow of the program, to check for errors and tabulate data. Data was then coded and entered on to the excel data file. The encoding was done in three stages namely: the identification page, followed by the Individual data for all households members and finally the household- based data. Specific data analysis methods such as frequency distribution analysis were employed to achieve specific objectives of the study. The following formula was used to calculate proportions of the indicators. 
Proportions $(\mathrm{X} \%)=(\text { Magnitude of the affected }(\mathrm{Z}))^{*} 100$

Total number (Y)

Where $\mathrm{X} \%=$ Proportion, $\mathrm{Z}=$ Magnitude of the affected $\mathrm{Y}=$ Total number

\section{Map digitization, Processing and Mapping}

Encoded dataset was imported using Community-Based Monitoring Systems- Natural resources database [CBMS -NRDB] software to generate poverty maps. The required shape-files were not available from existing data sources, therefore the shape-files were digitized following a series of standard CBMS steps. Ones the digitization and encoding was finalized; household unmet needs were mapped using core indicators. This was done by importing data from the excel file to CBMS-NRDB for mapping and matching the names under import column with those under attributes following four ranges as shown below. In addition, four color schemes Green, Light green, Light red and Red were used in the legend to display the magnitude of vulnerability. Where green $=$ performing better than other villages, and Red =performing worse than the others I villages in terms indicators.

1st range maximum value: ((Ward value [X.Y]-minimum value of all villages [0]) / 2) + minimum value of all villages [0])

2nd range minimum value: $=1$ st range maximum value

2nd range maximum value $=$ Ward data $[X . Y]$

3rd range minimum value: $=2$ nd range maximum value

3rd range maximum value: (maximum value of all villages [100] - Ward data [X.Y.]) / $2+$ ward1data( [X.Y.]

4th range minimum value: $=3$ rd range maximum value

4th range maximum value: 100 (always 100 since the percentages ranges from 0-100)

\section{Data validation}

The results of the census were presented in a community forum where the extent of multidimensional poverty was discussed, disorganized and explained. At this point appropriate interventions were also identified. Presentation of the data to the community was vital to ensure accuracy and to get a buy-in for future interventions. It also helped to identify eligible beneficiaries for future intervention strategies.

\section{Ethical considerations}

The researcher communicated the aims and purpose of the study, the implications, and possible risks for involvement in the study to respondents. This was done in order to uphold research ethics, ensure conformity to the ethical requirements and secure informed consent. Approval to undertake the study was sought and granted from the Local municipalities and local structures. Even though the full participation was required during the exercise the respondents were informed of the fact that they had the right to withdraw from the study at any time. 


\section{Results of The Study}

Population demography. Table 1 below shows population demography by age category. A total of 1534 households in Ward 1, making up a total of 6651 household members were interviewed. Results shows that, youth population ages 0 to 35 years old counted the highest with an average of 62.80 . Out of this category 52.07 were most likely to be female and 47.30 male. The age group above 35 years old was 30.08 of which 34.7 were female and 29.3 were male. This information is important for municipal youth and gender targeted planning and budgeting process. It also demonstrates that the potential lies within the younger generation. The Municipality planning processes should therefore be based on the above reality.

Table 1. Population distribution by age group, Ward 1, G. Tzaneen, Limpopo, 2013

\begin{tabular}{llllllllll}
\hline \multirow{2}{*}{$\begin{array}{l}\text { pgrou } \\
\text { Age }\end{array}$} & \multicolumn{2}{l}{ Magnitude } & \multicolumn{3}{c}{ Row propotion } & \multicolumn{3}{c}{ Column propotion } \\
\cline { 2 - 12 } & Male & Female & Total & Male & Female & Total & Male & Female & Total \\
\hline 0-2 yrs. & 149 & 155 & 304 & 49.0 & 51.0 & 100.0 & 4.7 & 4.4 & 4.6 \\
\hline 3-5 yrs. & 221 & 267 & 488 & 45.3 & 54.7 & 100.0 & 7.0 & 7.6 & 7.3 \\
\hline 6-17 yrs. & 714 & 739 & 1,453 & 49.1 & 50.9 & 100.0 & 22.7 & 21.1 & 21.9 \\
\hline 18-35 yrs. & 1,140 & 1,216 & 2,356 & 48.4 & 51.6 & 100.0 & 36.3 & 34.7 & 35.4 \\
\hline$>36$ yrs. & 921 & 1,129 & 2,050 & 44.9 & 55.1 & 100.0 & 29.3 & 32.2 & 30.8 \\
\hline Total & 3,145 & 3,506 & 6,651 & 47.3 & 52.7 & 100.0 & 100.0 & 100.0 & 100.0 \\
\hline
\end{tabular}

Energy Accessibility by Households. Table 2 below shows energy accessibility by household. Of the 1534 household interviewed, 91.2 were accessible to electricity grid from Eskom. However, an average of 10.0 would normally use candle/kerosene lamp for lighting, 86.51 used firewood for cooking and 91.53 for heating. These findings demonstrate that even though South Africa rural households receive subsidized electricity tariffs, provided as a free basic allowance; rural households tend to incorporate electricity into their domestic energy, primarily using electricity for lighting. Further investigations revealed that the employed and self-employed moderately relied on energy from electricity grid but harvested fuel-wood to supplement electricity for domestic use. Those in the unemployed category relied mainly on traditional sources of energy such as fuel-wood and cow dung for multiple purposes, such as cooking, water-heating and lighting while others use paraffin (kerosene). Of the 1534 household interview 66.49 used the prepaid electricity consumption methodology. This method is found be to be easier by the household as household have control of the payment frequency and amount consumed. Investing by the local municipality on programmes that promote restoration of rural forests could also ease other environmental challenges resulting from deforestation for wood for fuel.

Table 2: Magnitude and Proportion of Households, by energy accessibility Ward 1, G. Tzaneen, Limpopo, 2013

\begin{tabular}{lll}
\hline Energy access & Magnitude & Proportion \\
\hline Electricity Accessibility & 1399 & 91.2 \\
\hline Candle as light energy source & 153 & 10.0 \\
\hline Firewood as energy for cooking & 1327 & 86.51 \\
\hline Electricity energy for cooking & 195 & 12.71 \\
\hline Firewood as source for heating & 1404 & 91.53 \\
\hline Prepaid for consumption & 1020 & 66.49 \\
\hline
\end{tabular}

Figure 1 further shows proportion of firewood consumption as source of energy for cooking by village. Marapalala and Manswa villages had majority household using fire wood as source of energy for cooking 
consumption rate of 80.1 and 120.0 followed by Senakwe and Moloko color pink, 60.1 and 80.0. Senopelwa and Pelane moderated consumption between 30.0 and 60.0. Matipane had the lowest rate of 0.0 to 30.0.

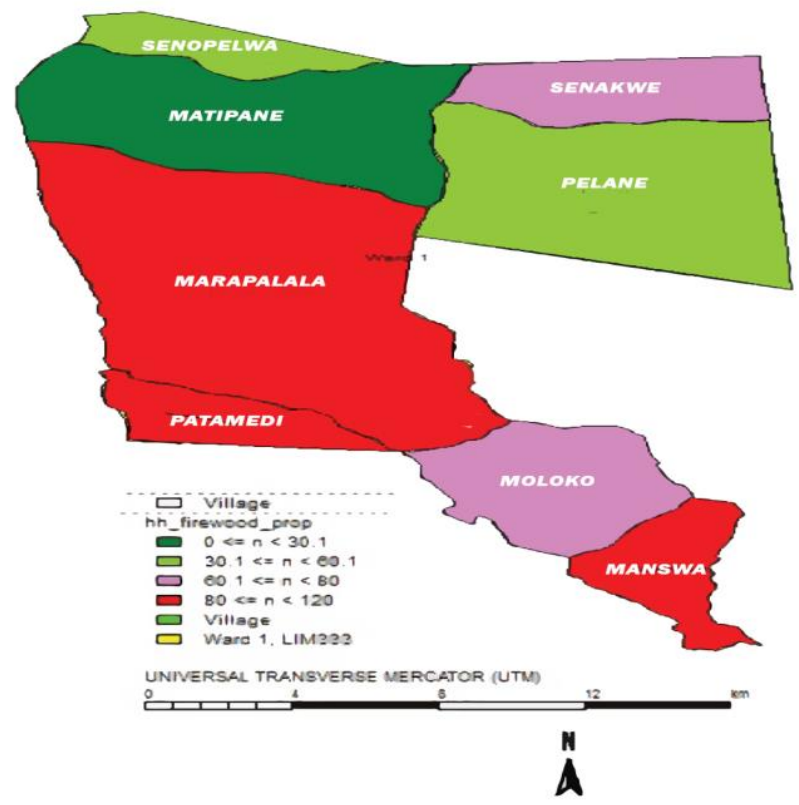

Figure 1. Proportion of households who use firewood as source of energy for cooking Ward 1, G. Tzaneen, Limpopo, 2013.

Safe water accessibility. Table 2 show that an average proportion of 68.97 of 1534 households interviewed had communal piped water. Indicating that of every 100 households, 68.97 accessed communal pipe water, 14.02 had rain water tank, 3.91 accessed river / stream, 2.67 had piped water in the yard and 4.69 had bore-hole. Household, who accessed communal piped water, indicated that most of the time they did not have water due to broken pipes or lack of service by local municipality. Moreover, in times when water was available it was not drinkable due to bad test or being soiled. The same problems was encountered with households with municipal water tanks. Those who did not access communal, water tanks or water pipes in the yard were more likely to access river/ stream or buy from neighbors. Further investigation revealed that those who had no access to safe water fell under the unemployed and /or depended on social security for survival.

Table 2 : Magnitude and Proportion of Households, by safe water accessibility Ward 1, G. Tzaneen, Limpopo, 2013

\begin{tabular}{lll}
\hline Variables & Magnitude & Proportion \\
\hline Piped water inside house & 3 & 0.2 \\
\hline Piped water in Yard & 41 & 2.67 \\
\hline Communal piped water & 1,058 & 68.97 \\
\hline Borehole & 72 & 4.69 \\
\hline Water tank & 215 & 14.02 \\
\hline River/Stream & 60 & 3.91 \\
\hline Other ( buy) & 19 & 1.24 \\
\hline Buy & 66 & 4.3
\end{tabular}

Source: CBMS Census, Ward 1, G. Tzaneen, 2013. 
Figure 2 below compares the performance of villages in relation to accessibility for safe water by color schemes and proportions. Marapala, Moloko and Manswa villages had the highest number of households with no adequate safe water with a range of between 81.8 to 100 , followed by Penale, Senakwe and Senopela with range of 63.5 to 81.8. Matipane had the lowest with 0.0 to 31.8. The results show that quick intervention is required for Marapalala, Moloko and Manswa by Local municipality through specific households targeting.

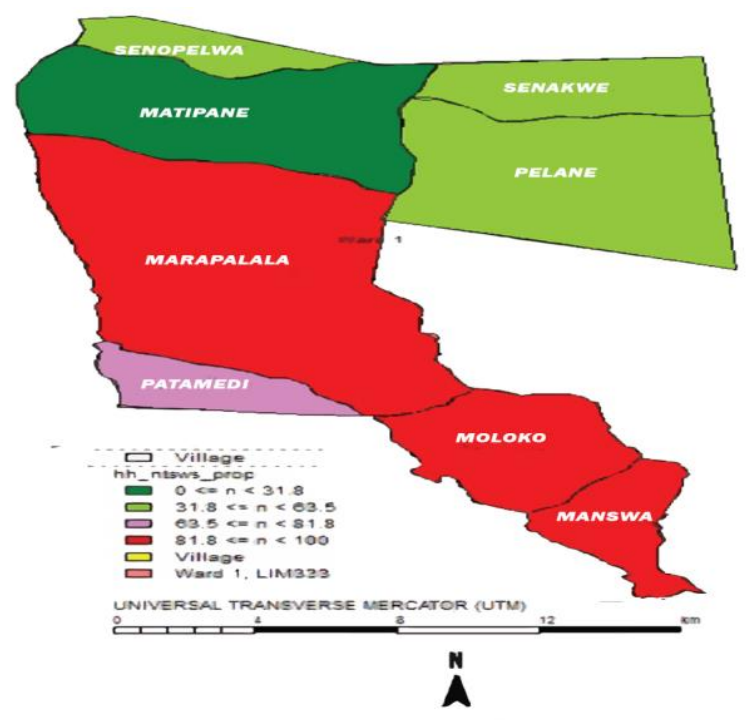

Figure2. Proportion of households, with inadequate safe water by Village, Ward 1, G. Tzaneen, Limpopo, 2013.

Sanitary toilet accessibility. Table 3 below shows that of the 1534 household interviewed, 52.82 had pit latrine without ventilation. 24.10 accessed bush, while 0.83 accessed bucket toilet system. Only 5.0 accessed either flush toilets connected to sewage or flush toilet with septic tank. Of those interviewed 10.19 and 6.99 were likely to access ventilated improved pit latrines (VIP), or pit toilets with ventilation respectively. Households who did not have access to toilet were more likely to utilising bushes and /or neighbours' facilities, which at times would be a pit toilet without ventilation. Households, who used bushes beside the river, were more likely to contaminate water causing health hazard to the community. Further investigations revealed that majority of the respondents who did not have toilets were likely to live in traditional dwelling and/or were not employed.

Table 3 : Magnitude and Proportion of Households, by sanitary toilet facilitiesWard 1, G. Tzaneen, Limpopo, 2013

\begin{tabular}{lll}
\hline Variables & Magnitude & Proportion \\
\hline Flush Toilet connected to sewage & 62 & 3.97 \\
\hline Flush Toilet with septic tank & 15 & 1.03 \\
\hline Ventilated improved pit latrines(VIP) & 159 & 10.19 \\
\hline Bush & 361 & 24.10 \\
\hline Pit toilet Without Ventilation & 813 & 52.82 \\
\hline Pit toilet With Ventilation & 108 & 6.99 \\
\hline Bucket Toilet system & 12 & 0.83 \\
\hline
\end{tabular}

Source: CBMS Census, Ward 1, G. Tzaneen, 2013 
Figure 3 below shows severity of lack of accessibility to sanitary toilets by village. Marapalala, Manswa and Senakwe villages had the highest number of households with no adequate sanitary toilets with range of between 81.8 to 100.0 or red, followed by Moloko and Senopelwa with range of 63.5 to 81.8 or Light green and Pelane and Matipane the lowest with 0.0 to 31.8 or dark green. This indicates that for any municipality planning the focus must start with Marapalala, Manswa and Senopelwa.

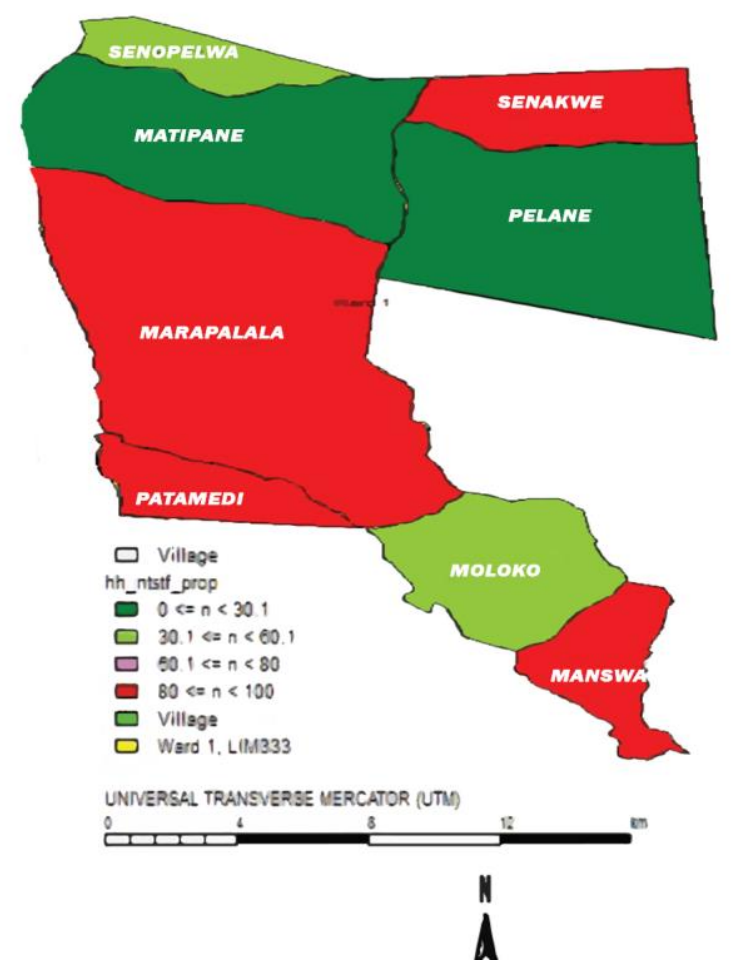

Figure3.Proportion of households, with inadequate sanitary toilets by village, Ward 1, G. Tzaneen, Limpopo, 2013

\section{Implication For Use of CBMS Generated Data In Integrated Development Planning}

In this study, the main objective was to firstly examine multidimensional poverty on a sample of basic services and to further assess the implication of CBMs generated data in Integrated Development Planning. An integrated development planning gives an overall framework for development through coordination of the work of local and other spheres of government in a coherent manner to improve the lives of the poor (IDP, 2000). Community -based system captures multiplicity of poverty conditions in the local area. This stud response from DBSA,(2000) which states that the key consideration in the intergarted development planning process are that the priority issues are derived from the existing local situation and focus on problems from the municiplaity, the community and development practitioners. Moreover, the data can be used during the integrated development planning to coordinate the work of local and other spheres of government. Study results demonstrate that multidimensional poverty exists in Ward 1 in Tzaneen local municipality. The results further demonstrate various implications for use of CBMS generated Data both in practice and research in integrated development planning.

\section{Implication for practice}

The first major practical implication of the study is that it provides a much needed empirical data on multidimensional poverty realities at local levels, who are the poor, where they are and what contributes to their poverty. The CBMS generated data is therefore vital for formulating appropriate integrated plans; provide the basis for allocation of resources and targeting the right beneficiaries. This information is important for 
integrated development planning given that the survey by statistics South Africa data is sampled and disaggregated at national and sometimes at provincial level. Moreover, national disaggregated data does not provide detailed local information useful for local planners. The study response to the call made by Reyes and Due, (2009) and statistics South Africa (2008) that the lack of appropriate local information about the poor in majority of developing world hinders development planning and constrains efforts to monitor change.

A second important implication is derived from the uniqueness of CBMS generated data in terms of disaggregation across population sub-group and geo-political. An analysis of such data can be used to assess policy implication by sub-groups and geo-politics and allow policy-makers and the development planners to make informed decisions based on the actual data at the ground. The study responds to the concern by statistics South Africa, 2008 which stated that Poverty data is key to evidence based policy development and for setting appropriate reduction strategies. Policy Interventions need to take into account sources of potential government failure and differences in local conditions to avoid perverse results (World Bank, 2005).

A third implication is that the CBMS generated data capture multiple dimension of poverty based on a set of carefully selected indicators. This can help analyze the dimension levels by households and village. Moreover CBMS-NRDB generated maps show a simple color scheme that makes it easier to interpret and understand both the magnitude of poverty and quick reference on beneficiary targeting. Such information can be used by planners to prioritize projects, for budget allocation and to prepare annual development plans. The study response to several calls by various authors such as Cantillon and Nolan,( 2001) who stated that income may not adequately capture differences in living standards and may not always be a reliable measure of exclusion. Magasela, (2005), who stressed the need for research to focus on the use of indicators of multiple deprivation in South Africa rather than absolute or minimalistic based poverty lines. Bhorat and Kanbur (2006) who argue that income and expenditure based approach presents only one of many dimensions to the measurement of wellbeing in South Africa

The fourth important implication is that CBMS generated data if conducted on ongoing basis can produce panel data that could be used by local planners to monitor impact of interventions disaggregated across subgroups or geo-political levels at local levels over a five year life span of the Integrated development plans. The data can therefore provide baseline information for preparing integrated development funding proposals and reports. This answers the call by (Statistics South Africa, 2016) that state that the 5-year census gap does not provide current status of poverty at household levels making it difficult for the local municipalities to undertake effective planning and fundraising.

\section{Implication for future research}

The study offers the opportunity to refine and expand the usage of CBMS data to other areas such as entrepreneurship, gender based budgeting, climate change among others to have a better understanding of the usability of CBMS generated data in Development considering its flexible nature.

\section{Limitations of the Study}

These findings are based on the study on one Ward, therefore a rollout to other Wards and local municipalities for broad conclusions. It is worth noting that certain characteristics for instance, employment and civil status were only available at the household level. Member data where appropriate would have given a more comprehensive outcome in such cases. 


\section{Discussions and Conclusions}

The study results revealed some similarities with other imperial findings.

Firstly the study results revealed of 3-5 years age category 82.3 were not attending any educational institution. This is an area of concern considering that this is the foundation level for child development. The National Planning commission 2011 argued that the promotion of learners who were not ready in primary and early secondary phases led to substantial dropout before Matric (National Planning Committee [NPC] 2011). In its vision for 2030, the South Africa government plans to set up early childhood development centers that would be properly monitored. The author concludes that CBMS generated data can be used by Local Municipality to craft intervention strategies for3-5 years attendance.

Secondly study results also showed that safe drinking water accessibility was a challenge. The CBMS findings portrayed similar pattern with Integrated Development Plans [IDP], (2012), which state that approximately 26\% of the population did not have access to clean water. The author concludes that is a need for implementing a well-crafted policies and strategies for deteriorating water quality and ensuring greater access to water backlog (National Planning Committee [NPC] (2011).

Thirdly the study findings show that, Community based can generate data and maps that is effective for Integrated Development Planning. The information can also be used to assess poverty policy implications at local levels.

Finally CBMS should be viewed as a complement and not a substitute, to national-level sample surveys. Furthermore indicators, data-collection methodology and validation must be adapted to local conditions and developed over time. Critical to its success is the fact that enabling conditions need to exist for CBMS to be effectively institutionalized ( Reyes and Due, 2009).

We recommend that Local municipality should consider using CBMS generated data as a baseline for integrated development plans, beneficiary targeting monitoring development progress and to complement other National surveys data.

\section{Acknowledgement}

This work was carried out with a grant from the Poverty and Economic Policy (PEP) Network supported by the Government of Canada through the International Development Research Centre (IDRC), and the Canadian International Development Agency.

\section{References}

Bhorat, H., and Kanbur, R., 2005, Poverty and well-being in post-apartheid South Africa: an overview of data, outcomes and policy, working Paper No. 05/101, Cape Town: Development Policy Research Unit, University of Cape Town.

Cantillon, S., and Nolan, B.,2001, Poverty within households: measuring gender differences using nonmonetary indicators. Feminist Economics, 7,5-23.

Carrim, Y,2001, Bridging the gap between the ideas and practice: challenges of the new local government system. Umrabulo, May 10.

Creswell, J. W., Plano Clark, V. L., Gutmann, M., and Hansan, W., 2003, Advanced mixed methods research designs. In: Tashakkori, A. and Teddlie, C. (editors), Handbook of mixed methods in social behavioral research, (Thousand Oaks, CA, Sage), pp.209-240.

DBSA., 2000, Building developmental local government. development report 2000. Development Bank of Southern Africa, Midrand, SA. 
Hirschowitz, R., Orkin, M., and Alberts, P., 2000. Key baseline statistics for poverty measurement. In R. Hirschowitz (Ed.), Measuring poverty in South Africa. Pretoria: Statistics South Africa, pp. 5-52.

Integrated Development Plans.,2012, Integrated development plans 2012/13-2016/17 [Draft]. Tzaneen: Tzaneen Local Municipality.

Integrated Development Plans,2007, Mutale local municipality integrated development plans. Mutale, Vhembe District: Mutale Local Municipality.

Litman, Todd., 2006, Planning principles and practices, victoria transport policy institute. accessed at <http://www.vtpi.org/planning.pdf $>$ 4-8 - 2017.

Magasela,W.,2005, Towards Constitutional based definition of Poverty In post-Apartheid South Africa. State of Nation, South Africa,2005-2006. HSRC Press, 2005.

May, J.,2001, An elusive consensus: Definitions, measurement and analysis of poverty. In A. Grinspun (Ed.), Choices for the poor: Lessons from national poverty strategies. New York: United Nations Development Programme, pp. 23-54.

McIntyre, D., Muirhead, D., \& Gilson, L., 2000, Geographic patterns of deprivation in South Africa: Informing health equity analyses and public resource allocation strategies. Health Policy and Planning. 17, 30-39.

National Planning Commission., 2011, National development plan vision 2030, Pretoria, South Africa: The Presidency.

Noble, M., Wright, G., \& Cluver, L., 2006, Developing a child-focused and multidimensional model of child poverty for South Africa. Journal of Children and Poverty, 12(1), 39-53.

Oosthuizen, M., 2011, Estimating poverty lines for South Africa. Retrieved from www.infr.gov.za on 12/7/17 from Department of Social Development.

Partnership for Economic Policy Network, 2009, Building partnerships, strengthening capacities and Fostering responsive and accountable governance. Proceedings of the 2009 national conference of Community based monitoring system. Philippines. December. pp 1-257.

Reyes, C., \& Due, R., 2009, Fighting poverty with facts: Community-based Monitoring system. Ottawa, ON: International Development Research Centre.

SALDRU, 2008, The South African national economic dynamic study (NIDS): lessons from the international experience.

Scott, C.,2000, Measuring up to the poverty measuring problems: The role of statistics in evidence based policy making. UK: London school of Economics.

South Africa Local government: municipal structure amendment Bill of 2016. Accessed on12/7/17 from WWW.gov.za/documents/local-government-municipality-structures-act.

South Africa Local government: Municipal structure amendment act1 of 2003. Accessed on 12/7/17 from WWW.gov.za/documents/local-government-municipality-structures-act.

South Africa Local government: Municipal structure amendment act 32 of 2000. Accessed on 12/7/17 from WWW.gov.za/documents/local-government-municipality-structures-act

South Africa Local Government: Municipal Structures Act 117 of 1998. Accessed on 12/7/17 from WWW.gov.za/documents/local-government-municipality-structures-act.

South Africa White paper on Local Government. Accessed on 12/7/17 fromwww.cogta.gov.za/cgta_2016/wpcontent.../white paper_local-Gov_1998.

SPII ,2005, The Measurement of Poverty in South Africa Project: Key issues from statistics South Africa (2000) Measuring poverty in South Africa, Pretoria: Statistics South Africa.

SPII ,2007, The Measurement of Poverty in South Africa Project: Key issues. Pretoria: Statistics South Africa.

Statistics South Africa. (2008). Community Survey 2007: methodology, processes and studies in poverty and inequality. Johannesburg, South Africa: Statistics South Africa.

Statistics South Africa,2007, General household survey 2006. Pretoria South Africa: Statistics South Africa.

Statistics South Africa,2007,Income and expenditure of Household survey 2005/2006 statistical release. Pretoria, South Africa: Statistics South Africa. 
Tarozzi, A., \& Deaton, A., 2007, Using census and survey data to estimate poverty and inequality for small area. The review of Economic Statistics, 61(1), 146-149.

United Nations, 2005, A handbook on poverty statistics: Concepts, methods and policy use. NY: United Nations.

United Nations ,2006, Towards achieving sustainable growth and development through vision 2014; united nations development assistant framework for South Africa 2007-2010.NY: United Nations.

United Nations Development programme ,2000, Human Development report 2000: United nations Development programme, New York: Oxford University Press.

Woolard, I., \& Leibbrandt, M., 2006, Towards a poverty line for South Africa: A background note. Cape town, South Africa: Southern Africa Labor and Development Research Unit. Retrieved from http://www.treasury.gov.za.

World Bank, 2016, Poverty and shared responsibility. Taking on inequality. World Bank. Washington DC.USA.

World Bank,2005, World Development Report 2005: A better investment Climate for everyone. Volume 33-35. Oxford University Press, World Bank NY USA. 